\title{
Serviço Social e saúde:
relação antiga, desafios
presentes
}

Social work and healthcare: old relationship, current challenges Viviane Cristina Barbosa*

\begin{abstract}
Resumo - O presente artigo tem como objetivo problematizar o cotidiano de trabalho dos assistentes sociais na área da saúde, especificamente num hospital universitário do Rio de Janeiro. Resulta de um estudo realizado sobre as demandas atendidas por esses profissionais nos diversos setores da instituição, através de relatos em livro de ocorrência, fichas de estudo social e reuniões de equipe, cuja análise dos dados obtidos referencia-se na teoria social crítica marxiana. Nesse contexto, longe de oferecer resultados conclusivos, pretendemos fomentar a reflexão crítica acerca da superação de demandas emergenciais, burocráticas e rotineiras presentes na profissão desde sua gênese.

Palavras-chave: Serviço Social; saúde; cotidiano profissional.

Abstract - This article aims to problematize the daily work of social workers in the healthcare area. More specifically, in a university hospital in Rio de Janeiro. It is the result of a study carried out by demand of those professionals in various sectors of the institution, through reports on occurrence books, social study notes, and team meetings. The analysis of the data obtained has as reference Marxian critical social theory. In this context, far from offering conclusive results, we intend to promote critical reflection about overcoming the emergency, bureaucratic, and routine demands that have been present in the profession since its early days. Keywords: social work; healthcare; professional daily life.
\end{abstract}

* Doutora em Serviço Social (UFRJ). Assistente Social da Universidade Federal do Rio de Janeiro - UFRJ. E-mail: vivicristinabarbosa@gmail.com. ORCID: https://orcid.org/0000-0003-3227-3540. 


\section{Introdução}

O presente artigo resulta de uma série de inquietações que perpassam nossa trajetória profissional, mediante os desafios e limites de nossas ações, nas relações estabelecidas com a categoria profissional, com os usuários dos serviços de saúde e com os demais profissionais que compõem a equipe nesse campo. Trata-se de um relato de experiência, no qual pretendemos problematizar algumas ações desenvolvidas pelos assistentes sociais na área da saúde, especificamente inseridos num hospital universitário de alta complexidade do Rio de Janeiro.

A partir de um breve levantamento de demandas que chegam ao Serviço Social do referido hospital, através dos relatos em livro de ocorrência, fichas de estudo social e reuniões periódicas da equipe, fica claro que muitas destas são de cunho burocrático e/ou puramente administrativo. Sendo assim, as reflexões aqui contidas resultam dos diversos atendimentos realizados aos usuários da instituição e a seus familiares nesse cenário, assim como das demais atividades exercidas pelos assistentes sociais neste espaço universitário (que alia pesquisa, ensino, extensão e assistência), tendo como referencial teórico a teoria social crítica marxiana.

O cotidiano de trabalho dos assistentes sociais nesta área, seja nas unidades de internação, seja no setor de emergência ou em ambulatórios, é atravessado por desafios permanentes, numa constante luta pelo reconhecimento e pela defesa da saúde como política pública, articulada às demais políticas que compõem a seguridade social brasileira. Essa luta vai de encontro à supremacia do saber médico, inscrita na formação profissional da primeira escola de Serviço Social na América Latina, mais precisamente no Chile, em 1925: formar profissionais para serem subtécnicos, dispostos a colaborar com os médicos.

A defesa por um efetivo Sistema Único de Saúde (SUS), afirmada pelo Movimento de Reforma Sanitária brasileiro, tem como contraponto o desmonte das políticas sociais, um verdadeiro processo de contrarreforma, iniciado logo após a promulgação da Constituição Federal de 1988, com o início da ofensiva neoliberal brasileira em 1989 e desenvolvida nos anos posteriores. Assistimos ao crescimento da pobreza e da desigualdade em nosso solo, com a falácia de que o crescimento econômico é necessário para redução e combate do pauperismo, quando sabemos muito bem com "quem" estamos lidando: produção exponenciada de riqueza e produção reiterada de pobreza - traço próprio da dinâmica de produção capitalista.

Dessa forma, nosso objetivo é oferecer subsídios para fomentar esse debate a partir da experiência vivenciada, refletindo sobre o trabalho realizado pelos assistentes sociais, com vistas à superação dessa subalternidade profissional, nesse ambiente em que ainda impera o saber médico. 


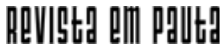

\} SERVIÇO SOCIAL E SAÚDE - BARBOSA, V. C. \}

DOI: 10.12957/REP.2019.45242

\section{O processo de defesa da saúde como direito de todos e dever do Estado}

A saúde, definida como política pública na Constituição Federal de 1988, em seu art. 196, está preconizada como direito de todos e dever do Estado (BRASIL, 1988). Nesse mesmo artigo, prevendo ainda o acesso universal e igualitário às ações e serviços para sua promoção, proteção e recuperação, indica-se a possibilidade de ir além do sanitarismo campanhista e das práticas curativas anteriores.

Essa concepção de saúde como direito, que deve ser garantido mediante políticas sociais e econômicas que busquem a redução do risco de doenças e de outros agravos, tem como pressuposto o resultado da luta do Movimento de Reforma Sanitária brasileiro, que desde a década de 1970 vem desenvolvendo debates na direção de defender o conceito de saúde para além da ausência de doenças.

A $8^{\text {a }}$ Conferência Nacional de Saúde, realizada em Brasília no ano de 1986, representa o marco dessas discussões. Em seu relatório final, apresenta a saúde como direito:

Em seu sentido mais abrangente, a saúde é resultante das condições de alimentação, habitação, educação, renda, meio ambiente, trabalho, transporte, emprego, lazer, liberdade, acesso e posse da terra e acesso a serviços de saúde. É, assim, antes de tudo, o resultado das formas de organização social da produção, as quais podem gerar grandes desigualdades nos níveis de vida. (BRASIL, 1987, p. 4).

O mesmo relatório sinaliza a necessidade de que o Estado deve assumir uma política de saúde integrada às demais políticas sociais e econômicas, assegurando os meios para efetivá-la. Propõe, ainda, a reestruturação do Sistema Nacional de Saúde, com a criação de um Sistema Único de Saúde (SUS), tendo como alguns de seus princípios, entre outros: a) a descentralização na gestão dos serviços; b) a integralização das ações, superando a dicotomia preventivo-curativo; e c) a equidade em relação ao acesso dos que necessitam de atenção. É dessa forma que Passos (2017) reforça a mudança de paradigma na saúde, antes pautado no paradigma flexneriano, com ênfase na pesquisa biológica, na especialização médica, no individualismo, no curativismo e centrado no hospital, para um paradigma de produção social da saúde, no qual o estado de saúde é considerado como um processo em permanente transformação, apresentando profunda relação com as condições de vida.

Segundo Bravo (2007), a $8^{\text {a }}$ Conferência é considerada como préconstituinte da área da saúde, assim como introduz a sociedade no cenário da discussão. A autora destaca que o texto aprovado na constituinte, "após vários acordos políticos e pressão popular, atende em grande parte as reivindicações do movimento sanitário, prejudica os interesses empresariais 


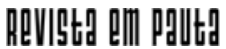

\} SERVIÇO SOCIAL E SAÚDE - BARBOSA, V. C. \}

DOI: $10.12957 /$ REP.2019.45242

do setor hospitalar e não altera a situação da indústria farmacêutica" (BRAVO, 2007, p. 93).

No rastro da Constituição Federal de 1988, iniciamos a década de 1990 com a promulgação da Lei Orgânica da Saúde (Lei ํo 8.080/90), acompanhada da Lei 8.142/90, que dispõe sobre a participação da comunidade na gestão do SUS - com as conferências e os conselhos de saúde - e sobre as transferências intergovernamentais de recursos financeiros na área da saúde.

A Lei no 8.080/90 possui como um de seus destaques o art. 0 4, § $2^{\circ}$, que trata da iniciativa privada: esta só poderá participar do SUS em caráter complementar, com preferência para as entidades filantrópicas e sem fins lucrativos, reforçando o dever do Estado na prestação dos serviços de saúde (BRASIL, 1990. Destaca-se, em relação aos seus princípios e diretrizes, a universalidade de acesso aos serviços de saúde em todos os níveis de assistência, a integralidade de assistência, entendida como conjunto articulado e contínuo das ações e serviços preventivos e curativos, individuais e coletivos, exigidos para cada caso em todos os níveis de complexidade do sistema, e a descentralização político-administrativa, com direção única em cada esfera de governo.

Embora as referidas legislações representem avanços na discussão da saúde como direito, abarcando boa parte das reivindicações do Movimento de Reforma Sanitária brasileiro, as mesmas enfrentaram desafios para sua efetivação desde suas promulgações, com o início da ofensiva neoliberal no Brasil, orquestrada pelo então Presidente do Brasil Fernando Collor de Mello, eleito em 1989, e amplamente desenvolvida nos governos posteriores: um verdadeiro processo de contrarreforma, tendo como eixo central o ajuste fiscal (BEHRING, 2008).

A esperança de reverter o cenário de contrarreforma do Estado com a eleição de Luiz Inácio Lula da Silva para a presidência do Brasil, e de sua sucessora, Dilma Roussef, caiu por terra em pouco tempo. Seguindo os rumos de seu antecessor, Fernando Henrique Cardoso, o Governo Lula deu continuidade à política neoliberal, com uma série de contrarreformas. No que diz respeito à seguridade social, além de encaminhar o processo de contrarreforma da previdência, dirigiu suas ações para programas de combate à pobreza, tendo como carro-chefe o Programa Bolsa Família, num processo de assistencialização da seguridade social, em que a política de assistência social é endeusada, numa espécie de "salvadora da pátria":

A centralidade que a assistência social possui nesse panorama, tendo a
execução de suas ações praticamente limitada aos programas de
transferência de renda, faz com que seja considerada como a salvadora
da pátria: os que não conseguem vender sua força de trabalho no mercado
têm nesses programas a oportunidade de obter uma renda mínima para
sua sobrevivência e de sua família, desde que seja considerado pobre
ou extremamente pobre (sob a análise de renda) e assuma o compromisso 


\section{ReVIStg a d P p putt}

\} SERVIÇO SOCIAL E SAÚDE - BARBOSA, V. C. \}

DOI: $10.12957 /$ REP.2019.45242

de cumprir com as condicionalidades impostas, dedicando seus esforços na participação de programas complementares (como os de geração de trabalho e renda), buscando sua 'emancipação'. (BARBOSA, 2013, p. 100).

Nesse cenário, a política de saúde sofreu diversos ataques. Bravo e Menezes (2011) destacam a persistência de algumas dificuldades em relação ao sistema, como a falta de viabilização da concepção de seguridade social e o desafio de construir práticas baseadas na integralidade e na intersetorialidade. Cislaghi (2011, p. 60-61) analisa, ainda que de forma preliminar, as implicações trazidas pela Empresa Brasileira de Serviços Hospitalares (EBSERH). Como uma das últimas ações do Governo Lula, a criação da EBSERH foi justificada pela necessidade de resolver o impasse dos terceirizados dos hospitais universitários federais (HUs), quando na verdade trata-se de uma medida que propõe a retirada da gestão dos hospitais universitárias das mãos das universidades.

Especificamente, na área da saúde, assistentes sociais enfrentam ainda o desafio em dar visibilidade ao seu trabalho, demonstrando o potencial de sua formação para os demais membros da equipe de saúde (e usuários), deixando claro quais são suas atribuições e competências nessa área, num ambiente onde o saber médico tem sempre prioridade.

\section{Serviço Social e saúde - relação antiga, desafios presentes}

O desafio em dar visibilidade ao trabalho realizado pelos assistentes sociais possui raízes, entre outros elementos, na criação da primeira escola de Serviço Social na América Latina. Em 1925, foi criada a primeira escola de Serviço Social na América Latina, mais precisamente no Chile, pelo médico Alejandro Del Rio. Enviado à Bélgica pela Junta Central de Beneficência de Santiago, Del Rio conheceu os centros de formação acadêmica daquele país. Suas inquietações residiam na necessidade de formação de um grupo diversificado de profissionais, com o objetivo de atender ao crescimento da intervenção estatal no campo da assistência social (CASTRO, 2003). Dessa forma, criou uma escola para formação de profissionais que pudessem trabalhar complementando as funções dos médicos.

A escola criada por Del Rio era laica, tendo como origem as necessidades de expansão estatal, num período de intensa combatividade operária, e não de uma aproximação com a Igreja Católica - essa aproximação será observada de forma concreta na criação da segunda escola chilena, a Elvira Matte de Cruchaga, em 1929:

A iniciativa de Del Rio parte de motivações sumamente específicas, inserida no campo de interesses da profissão médica. Como se sabe, e o próprio Dr. Del Rio se encarregou de explicitá-lo, o 'assistente social 


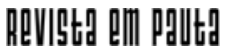

\} SERVIÇO SOCIAL E SAÚDE - BARBOSA, V. C. \}

DOI: $10.12957 /$ REP.2019.45242

deveria ser um subtécnico incumbido de colaborar diretamente com o médico'. Por mais que o perfil original da profissão, esboçado pela primeira escola chilena, se colocasse sob uma base doutrinária católica, o seu trabalho prático tinha um marco de ação bastante delimitado, pois, quase por definição, situava-se nos contornos da profissão médica. (CASTRO, 2003, p. 74).

Ainda segundo Castro (2003), embora a base doutrinária fosse comum às duas escolas, com uma relação próxima do Serviço Social belga, a escola Elvira Matte de Cruchaga, fundada em 1929, não limitou suas ações à área médica. No entanto, pensando em ações que pudessem responder às demandas de diversos setores, a escola visava à formação de visitadoras sociais católicas, de modo que essa formação dava ênfase aos cursos relacionados à área de saúde. Percebemos aqui o importante vínculo entre o Serviço Social chileno e a área de saúde, mas ressaltando o aspecto conservador dessa atuação.

O Serviço Social norte-americano, que influenciou o Serviço Social brasileiro a partir da década de 1940, apresenta também a relação da profissão com a área da saúde. Importante destacar aqui a figura de Mary Richmond, com a fundamental contribuição tanto para a institucionalização do ensino como para a profissionalização do Serviço Social, dando ênfase à abordagem individual (MARTINELLI, 2005). Richmond buscou "inspiração" no trabalho realizado por Florence Nightingale, considerada pioneira na enfermagem, para a formação de visitadoras domiciliares, em que o diagnóstico social ocupava um papel de destaque, através do inquérito individual realizado no próprio domicílio:

A firme convicção quanto à eficácia desse instrumento e à importância da visita domiciliar levou Mary Richmond a estabelecer como objetivo de seus primeiros cursos o preparo de visitadoras domiciliares (home visitors), o que absorvia e ampliava a idéia das 'visitadoras de saúde' (health visitors), criadas por Nightingale. (MARTINELLI, 2005, p. 109).

Esse trabalho, pautado numa doutrina funcionalista e positivista, direcionou o perfil dos profissionais formados nessa época nas escolas brasileiras, visando ao "ajustamento" dos indivíduos à sociedade. As ações na área da saúde seguiam o mesmo enfoque de abordagem individual e curativa, desde o processo de institucionalização e legitimação do Serviço Social no Brasil, com a criação e o desenvolvimento das grandes instituições sociais e assistenciais - a saúde ainda não era o setor de maior concentração de assistentes sociais. Com ações centradas em hospitais e ambulatórios, os assistentes sociais não foram absorvidos nos centros de saúde de imediato. A mudança desse quadro só começará a tomar corpo a partir de 1975, com o caráter contraditório entre demanda e oferta da ampliação dos serviços de assistência médica hospitalar (BRAVO; MATOS, 2004). 


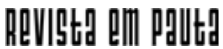

\} SERVIÇO SOCIAL E SAÚDE - BARBOSA, V. C. \}

DOI: $10.12957 /$ REP.2019.45242

Isso quer dizer que o processo de renovação do Serviço Social, iniciado na década de 1960, não teve articulação com o início do Movimento de Reforma Sanitária brasileiro, em 1970 . O processo de renovação iniciado no seio da profissão era de uma revisão interna, de negação do Serviço Social tradicional:

Ou seja, o processo de renovação do Serviço Social no Brasil está articulado às próprias questões colocadas pela 'autocracia burguesa', não sendo um processo desligado das mutações do mundo. Por outro lado, o processo de renovação foi um movimento de revisão interna, pouco articulado com as outras questões cruciais da sociedade. (MATOS, 2003, p. 87).

A aproximação do Serviço Social com o Movimento Sanitário foi iniciada na década de 1980, através da interlocução da profissão com a tradição marxista - vertente de intenção de ruptura. Mesmo que esta interlocução tenha sido iniciada de forma enviesada, é notável a postura crítica desses profissionais nas discussões desenvolvidas - embora mais presentes no âmbito acadêmico: a intervenção profissional não foi objeto primordial de discussão, mesmo que esta década tenha representado a maioridade intelectual da profissão.

Apesar dos avanços, o Serviço Social adentra os anos 1990 pouco articulado com o Movimento de Reforma Sanitária. Também é nessa década que a ofensiva neoliberal avança no país: o processo de contrarreforma em curso, com seu ideário de privatizações e focalização das políticas públicas, assim como a reestruturação produtiva, trazem novas demandas para os assistentes sociais. Sendo profissional assalariado, esse trabalhador é impactado pelas mudanças no mundo de trabalho, tais como os usuários que atende, tais como contratos terceirizados e precarização das relações de trabalho.

Com esse panorama, os desafios não se esgotam: a defesa da qualificação profissional, da sistematização da prática, da realização de cursos e de participação em eventos da categoria (como seminários e congressos) é constante em nosso cotidiano de trabalho, cotidiano esse compreendido como o espaço do imediato, presente em todas as esferas da vida do indivíduo (CARVALHO; NETTO, 2007). Tem como critério a funcionalidade, sendo fundamental a sua suspensão para romper com esse imediato aparente.

Essas questões se intensificam nos dias atuais, num desmonte perverso de direitos trabalhistas conquistados historicamente. Todavia, o poder de luta da categoria não enfraqueceu: são exemplos a Frente Nacional Contra a Privatização da Saúde, os fóruns de saúde e outros espaços de luta coletiva. No que diz respeito à nossa intervenção, mesmo com a publicação da versão final dos Parâmetros para atuação do assistente social na saúde (CFESS, 2010), ainda nos deparamos com o desafio de afirmar o assistente social como profissional de saúde, e não como um técnico que auxilia ou complementa o trabalho dos médicos. 


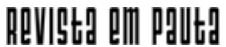

\} SERVIÇO SOCIAL E SAÚDE - BARBOSA, V. C. \}

DOI: $10.12957 /$ REP.2019.45242

\section{Intervenção profissional num hospital universitário}

A intervenção profissional num hospital universitário geralmente abrange quatro frentes de trabalho: assistência, pesquisa, ensino e extensão. Isso significa que os assistentes sociais nele inseridos prestam atendimentos aos usuários e suas famílias que buscam atendimento em diferentes setores, supervisionam estagiários, prestam preceptoria aos residentes multiprofissionais em saúde e também participam de diversas pesquisas, projetos e programas nesse ambiente.

Mencionamos anteriormente o que era exigido do profissional na criação da primeira escola chilena de Serviço Social: ser um subtécnico encarregado de colaborar com o trabalho dos médicos. Na realidade brasileira, Bravo (2007) também nos chama a atenção para essa característica ao relatar que, na reelaboração do setor saúde, o assistente social ficou marginalizado desse processo, sinalizando que tal omissão foi condicionada pela necessidade de redimensionamento teórico-metodológico pelos adeptos da intenção de ruptura. Outros condicionantes estão relacionados com a subalternidade do Serviço Social na área de saúde:

[...] cujo principal protagonista é o médico, com as demais profissões consideradas, durante muito tempo, como 'paramédicos', situação decorrente da divisão social do trabalho na sociedade capitalista. Outro aspecto ligado à subalternidade é a condição feminina da profissão. (BRAVO, 2001, p. 124).

Embora não sejam legislações específicas sobre o Serviço Social na saúde ${ }^{1}$, destacamos instrumentos fundamentais para o exercício profissional: o Código de Ética Profissional (CFESS, 1993) e a Lei de Regulamentação da Profissão, Lei no 8.662 (BRASIL, 1993), ambos de 1993, que apresentam valores, princípios, direitos, deveres, atribuições e competências profissionais. Entre os princípios éticos fundamentais do código de ética, encontramse o reconhecimento da liberdade como valor ético central e das demandas políticas a ela inerentes - autonomia, emancipação e plena expansão dos indivíduos sociais; a opção por um projeto profissional vinculado ao processo de construção de uma nova ordem societária, sem dominação-exploração de classe, etnia e gênero; e o posicionamento em favor da equidade e justiça social, que assegure universalidade de acesso aos bens e serviços relativos aos programas e políticas sociais, bem como sua gestão democrática. A Lei de Regulamentação da Profissão (BRASIL, 1993) apresenta competências e atribuições privativas, assim como o que é de competência dos Conselhos Regionais (Cress) e do Conselho Federal (CFESS).

\footnotetext{
1 Importante salientar que, na Resolução $287 / 98$ do Conselho Nacional de Saúde, o assistente social está relacionado como um profissional da área de saúde, assim como os biólogos, biomédicos, profissionais de educação física, enfermeiros, farmacêuticos, fisioterapeutas, fonoaudiólogos, médicos, médicos veterinários, nutricionistas, odontólogos, psicólogos e terapeutas ocupacionais.
} 


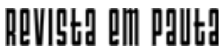

\} SERVIÇO SOCIAL E SAÚDE - BARBOSA, V. C. \}

DOI: $10.12957 /$ REP.2019.45242

Esses instrumentos, em conjunto com as diretrizes curriculares da Associação Brasileira de Ensino e Pesquisa em Serviço Social (Abepss), formam a base de sustentação do projeto ético-político do Serviço Social (PEP), cuja construção foi iniciada na transição da década de 1970 a 1980, tornando-se hegemônico na década de 1990 - o que não significa que seja único.

A intenção de ruptura com o conservadorismo não propiciou a ausência de tendências conservadoras ou neoconservadoras. Colaborou para a hegemonia do PEP o crescente envolvimento de segmentos cada vez maiores do corpo profissional nos fóruns, nos espaços de discussão e nos eventos profissionais, assim como a sintonização das linhas fundamentais do projeto, com tendências significativas do movimento da sociedade brasileira (NETTO, 2007b).

Os Parâmetros para a atuação de assistentes sociais na saúde (CFESS, 2010), com versão final em 2010, têm como finalidade referenciar a intervenção dos profissionais de Serviço Social na área da saúde. Fruto das discussões da categoria profissional, objetiva fortalecer o trabalho dos assistentes sociais na saúde, na direção dos projetos de reforma sanitária e ético-político profissional. Nele, estão expressas novas contradições que são criadas com a contrarreforma na saúde, que tentam não viabilizar o SUS constitucional. Nesse sentido, essas contradições direcionam as ações profissionais para práticas burocráticas, emergenciais. É primordial que os assistentes sociais tenham clareza de suas atribuições e competências, para que possam direcionar essas demandas para os setores competentes, refletindo sobre seu trabalho e sobre as condições sócio-históricas a que são submetidos os usuários dos serviços de saúde.

Pelo histórico de subalternidade na área de saúde, condicionado ainda pelas novas requisições postas pelo processo de contrarreforma do Estado, o cotidiano de trabalho dos assistentes sociais é permeado por funções que não são de sua atribuição e competência. Estas são realizadas, em parte, pela própria perversidade de intensificação do trabalho e, por outro lado, pela dificuldade de fortalecimento enquanto categoria profissional que compõe uma equipe de saúde.

O reconhecimento do trabalho realizado pelos assistentes sociais no hospital universitário do qual trata esse estudo perpassa uma série de questões que merecem atenção. O levantamento de demandas que chegam ao Serviço Social, em suas diversas frentes de trabalho, foi realizado através dos registros de atendimento em livros de ocorrência, fichas de estudo social e reuniões de equipe. Algumas dessas atividades estão inseridas num conjunto de ações que historicamente nos foi atribuído e que são defendidas inclusive por parte da categoria profissional. Através deste levantamento, as demandas mais frequentes são: 


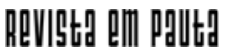

\} SERVIÇO SOCIAL E SAÚDE - BARBOSA, V. C. \}

DOI: $10.12957 /$ REP.2019.45242

1. Contatos telefônicos para solicitações diversas (entendimento com equipe médica; solicitação de fraldas, medicamentos e afins; comunicação de alta médica etc.): realidade comum nesse cenário, reforçada pelos profissionais da equipe de saúde sobre o pretexto da falta de aparelho telefônico e de tempo, ou mesmo de justificativas do tipo sempre foi assim. Quando existe a tentativa de esclarecimento com a equipe de saúde sobre a execução de tais atividades, não é raro ouvir que todo e qualquer contato familiar deve ser realizado pelo assistente social, afinal, ele é o profissional da família, sendo este um posicionamento inclusive de alguns assistentes sociais. Algo que poderia "explicar" esta demanda por contatos telefônicos pode residir na afirmação de que, nos primeiros anos de funcionamento do referido hospital, apenas o setor de Serviço Social possuía aparelho telefônico na unidade, sendo uma realidade superada ao longo dos anos, mas não a atividade em si. De acordo com Parâmetros para a atuação de assistentes sociais na saúde (CFESS, 2010), determinadas atividades não devem ser consideradas atribuições dos assistentes sociais, pois são ações que possuem um caráter eminentemente técnico-administrativo.

2. Solicitação de pedidos de transporte: essa é outra demanda constante no cenário do estudo, onde o Serviço Social condensa a maior parte das solicitações de transporte do referido hospital. As demandas mais frequentes são a marcação de transporte para transferência entre as unidades de saúde e para alta hospitalar. Como pode ser do assistente social a atribuição de agendar ambulâncias para transferências, em que as informações sobre o quadro clínico do paciente são imprescindíveis e de competência do médico? Aqui, mais uma vez, é fundamental nos atentarmos aos Parâmetros para a atuação de assistentes sociais na saúde (CFESS, 2010), onde está exposto que não podemos considerar como nossa atribuição ações que demandam uma formação técnica específica (de outras profissões da saúde) não contemplada na formação profissional dos assistentes sociais.

3. Convocação de familiares para comunicação de óbito (quando não a própria comunicação): comunicação de óbito é uma atribuição do médico, e não do assistente social. Segundo os Parâmetros para a atuação de assistentes sociais na saúde (CFESS, 2010), a equipe de saúde e/ou os empregadores, frente às condições de trabalho e/ou falta de conhecimento das competências dos assistentes sociais, têm historicamente requisitado a eles ações desse tipo, que não são atribuições dos mesmos.

4. Fornecimento de declaração de comparecimento quando o usuário não foi convocado para entendimento com o Serviço Social: o usuário vai à unidade para uma consulta médica ou para entendimento com outros profissionais, mas quando necessita de uma declaração de comparecimento, o mesmo é direcionado para o Serviço Social. Diante da negativa, o usuário "se revolta" e dirige-se a algum setor onde possa realizar uma queixa sobre o assistente social, e não sobre o profissional que o atendeu e deveria ter fornecido a declaração. Nesse ponto, mais uma vez tendo como 


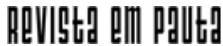

\} SERVIÇO SOCIAL E SAÚDE - BARBOSA, V. C. \}

DOI: $10.12957 /$ REP.2019.45242

referência os Parâmetros para a atuação de assistentes sociais na saúde (CFESS, 2010), é imprescindível que os assistentes sociais tenham clareza de suas atribuições, evitando dessa forma a realização de atividades que não são de sua competência.

Outras atividades próprias do referido hospital universitário também sofrem os efeitos do desmonte na área da saúde, que incidem diretamente no cotidiano profissional, como a supervisão de estágio de alunos de graduação e a preceptoria de residentes de Serviço Social.

Para além da assistência, é importante nos atentarmos para o hospital universitário como um local de ensino, pesquisa e extensão. No que diz respeito à supervisão de estágio, nem sempre o supervisor de campo consegue dedicar parte de sua carga horária para supervisão deste aluno, nem mesmo para a sistematização do plano de estágio, o que é extremamente contraditório diante deste campo. O aluno acaba por "caminhar" com o supervisor no atendimento das demandas espontâneas, sem um momento destinado à reflexão da prática realizada. Sendo o estágio supervisionado um componente central na formação profissional, que prevê a articulação essencial do supervisor de campo - supervisor acadêmico - com o aluno, nem sempre é possível estabelecer essa supervisão integrada, tanto pela dificuldade do assistente social em encontrar tempo disponível na sua rotina de trabalho, quanto na árdua tarefa de estabelecer uma concreta relação com a unidade de ensino.

Já em relação à preceptoria de residentes de Serviço Social, algo um pouco mais complicado se apresenta. Começando pela própria concepção de residência, na qual a pouca informação ou compreensão se o residente é aluno ou profissional está presente o tempo todo, uma vez que ele é um assistente social (provavelmente recém-formado), mas também é um aluno, pois trata-se de um curso de especialização com treinamento em serviço. A relação com as universidades nem sempre é possível de ser estabelecida, por diversos fatores, como a falta de carga horária docente ou mesmo pelo entendimento de que os residentes assumem funções nos serviços, como uma maneira de "utilizá-los" como mão de obra para suprir a falta de pessoal. Além desses fatores, apresenta-se para os assistentes sociais preceptores a função de orientador de Trabalho de Conclusão de Residência (TCR): com a dinâmica do trabalho realizado, dificilmente o profissional consegue liberação de carga horária para orientação deste residente e para sua própria qualificação, lembrando que mestre é a titulação mínima exigida para orientação de TCRs.

Enfim, não são poucos os fatores que dificultam o enfrentamento e a superação dos desafios e limites impostos ao trabalho dos assistentes sociais na área da saúde; porém, é fundamental a organização enquanto categoria profissional para repensar nosso trabalho neste campo tão rico que é um hospital universitário. Consideramos que o referido estudo, ainda que incipiente por tratar-se de um relato de experiência, nos provoca o 


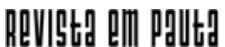

\} SERVIÇO SOCIAL E SAÚDE - BARBOSA, V. C. \}

DOI: $10.12957 /$ REP.2019.45242

desejo de aprofundamento do tema, não apresentando resultados específicos, e sim o objetivo de promover reflexões que possam nos direcionar na busca pela defesa da saúde como política pública e na defesa de nossas atribuições e competências profissionais.

\section{Algumas considerações}

Mediante o exposto neste breve artigo, apresentamos alguns elementos para reflexão acerca do papel do assistente social como trabalhador da saúde, esta compreendida como um direito de todos e dever do Estado. A definição de necessidades de saúde vai além do acesso a serviços e tratamentos médicos, pois, de acordo com Nogueira e Mioto (2007), para compreensão e definição destas necessidades é necessário levar em conta que elas são produtos das relações sociais, e destas com o meio físico, cultural e social. Nessa direção, é importante ter o olhar para a totalidade dos fenômenos sociais.

É fundamental ser um profissional crítico, que tenha clareza acerca de suas atribuições, competências, direitos e deveres, que apreenda a prática profissional em Serviço Social no conjunto das condições e relações sociais que atribuem sentido histórico à profissão, de forma que a mesma possa se legitimar como possível e necessária, atentando-se para as dimensões teóricometodológica, técnico-operativa e investigativa, assim como com o compromisso ético-político assumido. Para que a prática profissional nas instituições não se reduza ao atendimento imediato das demandas, faz-se necessária uma ruptura com atividades burocráticas e rotineiras: ir além das rotinas institucionais e buscar apreender o movimento da realidade, para detectar tendências e possibilidades nela presentes, passíveis de serem impulsionadas pelo profissional (IAMAMOTO, 2006).

O rompimento com essas práticas não se dá por acaso, de forma automática, como num passe de mágica. Depende do potencial de luta da categoria na tentativa de romper com a compreensão de que a profissão é uma espécie de evolução da filantropia, reiterando práticas conservadoras.

Todavia, como parte do processo reflexivo acerca das principais demandas apresentadas nesse estudo, é importante ater-se a elementos essenciais, com vistas a superar determinadas ações demandadas aos assistentes sociais nos hospitais universitários:

1. É imprescindível superar as ações emergenciais e burocráticas desenvolvidas pelos assistentes sociais. Essa superação só pode ser realizada a partir do fortalecimento da categoria e da clareza em relação ao significado social da profissão;

2. Ainda sobre as demandas emergenciais, os Parâmetros para a atuação de assistentes sociais na saúde (CFESS, 2010) nos indicam que, se estas não forem reencaminhadas para os setores competentes por meio do 


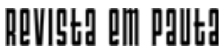

\} SERVIÇO SOCIAL E SAÚDE - BARBOSA, V. C. \}

DOI: $10.12957 /$ REP.2019.45242

planejamento coletivo elaborado na unidade, vão impossibilitar ao assistente social o enfoque nas suas ações profissionais. Por vezes, o receio em dizer não a uma determinada demanda coloca o assistente social num dilema maior (embora não deveria), que é a defesa de quais são as atividades de sua competência para os demais membros da equipe;

3. Sendo o hospital universitário um local de ensino, é fundamental a defesa pelo direito de qualificação desses profissionais. O $10^{\circ}$ princípio de nosso código de ética nos direciona à defesa desse direito: compromisso com a qualidade dos serviços prestados à população e com o aprimoramento intelectual, na perspectiva da competência profissional. O direto à qualificação profissional requer, entre outros fatores, entendimento com a equipe sobre sua importância para o trabalho realizado, incluindo a compreensão de que, em determinado período, a equipe deve se organizar para garantir esse direito ao profissional, assim como o atendimento das demandas apresentadas no cotidiano;

4. Outro elemento importante nesse processo é o estabelecimento de reuniões periódicas para organização e planejamento do trabalho a ser realizado. Esse, sem dúvida, é um trabalho em equipe, tendo em vista que o usuário não "pertence" a um determinado profissional. A sistematização da prática é fundamental nesse contexto;

5. Por fim, é necessário que os profissionais estejam em projetos de pesquisa e extensão, o que, no referido hospital, ainda é mínimo. Acreditamos que essa realidade possa ser superada através da maior participação da universidade, com programas de assessoria aos profissionais, com vistas ao desenvolvimento de estudos e publicações de artigos e afins, dando visibilidade ao trabalho realizado, que dificilmente ultrapassa os muros institucionais.

A questão é que a defesa de nossas reais atribuições e competências no campo da saúde exigem enfrentamentos que nem sempre o profissional quer ou pode ter, seja pela manutenção de seu emprego ou mesmo de sua prática de cunho conservador. Contrário a esses aspectos, reforça-se o compromisso de garantir espaços de debates e reuniões com as equipes de saúde, a fim de dar visibilidade ao trabalho que deve ser realizado, em favor dos usuários dos serviços de saúde. A tarefa é árdua, mas a luta é contínua. 


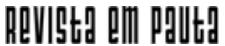

\} SERVIÇO SOCIAL E SAÚDE - BARBOSA, V. C. \}

DOI: $10.12957 /$ REP.2019.45242

\section{Referências}

BARBOSA, V. C. Assistência social: a linha do tempo entre o favor e a política pública. Tese (Doutorado em Serviço Social) - Programa de Pós-Graduação em Serviço Social, ESS/UFRJ, 2013, Mimeografado.

BEHRING, E. Brasil em contrarreforma: desestruturação do Estado e perda de direitos. São Paulo: Cortez, 2008.

BRAVO, M. I. S. Serviço social e reforma sanitária: lutas sociais e práticas profissionais. São Paulo: Cortez, 2007.

BRAVO, M. I. S.; MATOS, M. C. de. Reforma sanitária e projeto ético-político do Serviço Social: elementos para o debate. In: BRAVO, M. I. S. (org.). Saúde e Serviço Social. São Paulo: Cortez, 2004.

BRAVO, M. I. S.; MENEZES, J. S. B. de. A saúde no governo Lula e Dilma: algumas reflexões. In:In: BRAVO, M. I. S. (.org.). Saúde na atualidade: por um sistema único de saúde estatal universal, gratuito e de qualidade. Rio de Janeiro: Rede Sirius/Rede Sirius, 2011.

BRASIL. Relatório final de VIII Conferência Nacional de Saúde. Brasília, 1987.

BRASIL. Constituição Federativa do Brasil. Brasília, 1988.

BRASIL. Lei $n^{\circ}$ 8080/90. Dispõe sobre as condições para a promoção, proteção e recuperação da saúde, a organização e o funcionamento dos serviços correspondentes e dá outras providências. Brasília, 1990.

BRASIL. Lei $n^{\circ}$ 8.662/93. Dispõe sobre a profissão de assistente social e dá outras providências. Brasília, 1993.

CARVALHO, M. C. B.; NETTO, J. P. Cotidiano: conhecimento e crítica. São Paulo: Cortez, 2007.

CASTRO, M. M. História do Serviço Social na América Latina. São Paulo: Cortez, 2003.

CFESS. Código de ética profissional. Brasília: CFESS, 1993.

CFESS. Parâmetros para atuação de assistentes sociais na política de saúde. Brasília: CFESS, 2010.

CISLAGHI, J. F. Hospitais universitários federais e novos modelos de gestão: faces da contrarreforma do Estado no Brasil. In: BRAVO, M. I. S. (org.). Saúde na atualidade: por um sistema único de saúde estatal universal, gratuito e de qualidade. Rio de Janeiro: Rede Sirius, 2011.

IAMAMOTO, M. V. Serviço Social na contemporaneidade. São Paulo: Cortez, 2006. 


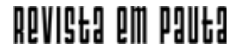

\} SERVIÇO SOCIAL E SAÚDE - BARBOSA, V. C. \}

DOI: $10.12957 /$ REP.2019.45242

MARTINELLI, M. L. Serviço Social: identidade e alienação. São Paulo: Cortez, 2005.

MATOS, M. C. de. O debate do Serviço Social na Saúde nos anos 1990. Revista Serviço Social e Sociedade, São Paulo, ano 24, n. 74, jul. 2003.

NETTO, J. P. A construção do projeto ético-político do Serviço Social. In: MOTA. A. E. (org.). Serviço Social e saúde: formação e trabalho profissional. São Paulo: Cortez, 2007b.

NOGUEIRA, V. M. R.; MIOTO, R. C. T. Desafios atuais do Sistema Único de Saúde - SUS e as exigências para os assistentes sociais. In: Serviço Social e saúde: formação e trabalho profissional. São Paulo: Cortez, 2007.

PASSOS, V. B. C. O SUS e a atenção primária em saúde (APS): análise da estratégia saúde da família em município de pequeno porte/Piraí, Rio de Janeiro. Dissertação (Mestrado em Serviço Social) - Programa de Pós-Graduação em Serviço Social, ESS/UFRJ, 2017. Mimeografado.

DOI: $10.12957 /$ rep.2019.45242

Recebido em 31 de agosto de 2017.

Aprovado para publicação em 31 de janeiro de 2018.

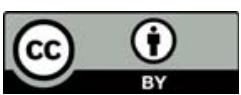

A Revista Em Pauta: Teoria Social e Realidade Contemporânea está licenciada com uma Licença Creative Commons Atribuição 4.0 Internacional. 